Published in final edited form as:

J Am Chem Soc. 2016 April 27; 138(16): 5194-5197. doi:10.1021/jacs.6b01023.

\title{
In Vivo Biosynthesis of a $\beta$-Amino Acid-Containing Protein
}

\author{
Clarissa Melo Czekster ${ }^{\dagger, \|}$, Wesley E. Robertson ${ }^{\ddagger}, \|$, Allison S. Walker ${ }^{\dagger}$, Dieter Söll ${ }^{\dagger} \S$, and \\ Alanna Schepartz ${ }^{*},+\ddagger$ \\ † Department of Chemistry, Yale University, New Haven, Connecticut 06520-8107, United States \\ ‡ Department of Molecular, Cellular, and Developmental Biology, Yale University, New Haven, \\ Connecticut 06520-8107, United States
}

$\S$ Department of Molecular Biophysics and Biochemistry, Yale University, New Haven, Connecticut 06520-8107, United States

\section{Abstract}

\begin{abstract}
It has recently been reported that ribosomes from erythromycin-resistant Escherichia coli strains, when isolated in S30 extracts and incubated with chemically mis-acylated tRNA, can incorporate certain $\beta$-amino acids into full length DHFR in vitro. Here we report that wild-type $E$. coli EF-Tu and phenylalanyl-tRNA synthetase collaborate with these mutant ribosomes and others to incorporate $\beta^{3}$-Phe analogs into full length DHFR in vivo. E. coli harboring the most active mutant ribosomes are robust, with a doubling time only $14 \%$ longer than wild-type. These results reveal the unexpected tolerance of $E$. coli and its translation machinery to the $\beta^{3}$-amino acid backbone and should embolden in vivo selections for orthogonal translational machinery components that incorporate diverse $\beta$-amino acids into proteins and peptides. E. coli harboring mutant ribosomes may possess the capacity to incorporate many non-natural, non- $a$-amino acids into proteins and other sequence-programmed polymeric materials.
\end{abstract}

Template-guided polymerization is the chemical foundation of the central dogma. It facilitates the evolution of natural biopolymers for greater fitness and, when co-opted for engineering, can optimize biopolymer sequence to define structure and promote function. The machine used for template-guided protein polymerization - the 2.5 MDa behemoth known as the ribosome-has been exploited for over 20 years to site-specifically incorporate $>150$ unnatural $a$-amino acids into proteins, in vitro, in cells, and in animals. ${ }^{1}$ Yet, even after two-plus decades of groundbreaking research, ${ }^{2}$ the potential of the translational apparatus remains underexploited, especially in vivo. ${ }^{3}$ Although a number of backbonemodified amino acids, including some $\beta$-amino and $\beta$-hydroxy acids, ${ }^{4}$ can be introduced into proteins by wild-type ribosomes in vitro using Flexizyme ${ }^{5}$ or chemically mis-acylated tRNAs, ${ }^{6,7}$ we know of no example in which a $\beta$-amino acid has been introduced into a

\footnotetext{
*Corresponding Author alanna.schepartz@yale.edu.

${ }^{\|}$C.M.C. and W.E.R contributed equally.

ASSOCIATED CONTENT

Supporting Information

The Supporting Information is available free of charge on the ACS Publications website at DOI: 10.1021/jacs.6b01023.

Supplementary procedures, figures, and tables (PDF)

The authors declare no competing financial interest.
} 
protein in a living cell. Proteins containing $\beta^{3}$-amino acids have enormous potential utility for biotechnology, as $\beta^{3}$-amino acid linkages can exhibit both enhanced protease resistance ${ }^{8}$ and uniquely altered immunogenicity. ${ }^{9}$

It was recently reported that ribosomes from certain erythromycin-resistant Escherichia coli mutants, when isolated in S30 cell extracts and incubated in vitro with the appropriate chemically mis-acylated tRNA, can incorporate certain $\beta^{3}$-amino acids into full length DHFR $^{10,11}$ Of five $\beta^{3}$-amino acids tested, $\beta$-Ar (Scheme S1A) exhibited the highest efficiency (18.4\% read-through). It has been widely assumed that many components of the translation machinery-especially aminoacyl-tRNA synthetase/tRNA pairs and EF-Tu, which generate and then deliver aminoacyl-tRNAs to the ribosome, respectively-would need to be reconfigured or upregulated ${ }^{4}$ before $\beta^{3}$-amino acids could be incorporated and elongated into proteins in vivo. Here we report that $\beta^{3}$-amino acids are adequate substrates for several wild type E. coli aminoacyl-tRNA synthetases and that one enzyme, phenylalanyl-tRNA synthetase (PheRS), can collaborate with wild type E. coli elongation factor Tu (EF-Tu) and ribosomes containing mutant peptidyl transferase centers to incorporate $\beta^{3}$-Phe derivatives into full length DHFR in vivo. E. coli harboring the most active P7A7 ribosome mutants are robust, with a doubling time only $14 \%$ longer than wild type. These results emphasize the unexpected tolerance of $E$. coli and its translation machineryto the $\beta$-amino acid backbone and should embolden in vivo selections for orthogonal translational machinery components that incorporate diverse $\beta$-amino acids into proteins and peptides in vitro and in vivo.

It has been known for a decade that some aminoacyl-tRNA synthetases can utilize $\beta$-amino acids (notably $\beta^{3}$-amino acids) as substrates, but no quantitative comparisons to natural substrates were ever reported. ${ }^{12}$ Thus, we began by analyzing the $a / \beta^{3}$-amino acid substrate specificity of five aminoacyl-tRNA synthetases that together represent four major subclasses and accept a diverse set of side-chains: methionyl-tRNA synthetase (MetRS, class IA), glutamyl-tRNA synthetase (GluRS, class IB), tyrosyl-tRNA synthetase (TyrRS, class IC), and phenylalanyl-tRNA synthetase and glycyl-tRNA synthetase (PheRS and GlyRS, respectively, class IIC). Using purified E. coli enzymes (Figure S1), we evaluated the $a-/ \beta^{3}$ amino acid specificity of the initial adenylation step, which activates the amino acid substrate, the two-step aminoacylation reaction (activation + acylation) as well as the deacylation reaction, which is also enzyme-catalyzed. All reactions were monitored using validated methods: Adenylation was monitored using a pyrophosphate exchange assay that measures adenylation in reverse through incorporation of $\left[{ }^{32} \mathrm{P}\right]$-pyrophosphate into ATP or a coupled assay monitoring pyrophosphate release (Figures S2 and S3). ${ }^{13}$ Aminoacylation and deacylation rates were monitored using $\left[a-{ }^{32} \mathrm{P}\right]-$ tRNA substrates and a chromatography assay that quantifies the amount of $\left[a-{ }^{32} \mathrm{P}\right]$-AMP (from deacylated tRNA) or [ $\left.a-{ }^{32} \mathrm{P}\right]-$ aminoacyl-AMP (from aminoacyl-tRNA) after P1 nuclease digestion. ${ }^{14}$

All aaRS enzymes evaluated prefer $a$-amino acid substrates during the adenylation phase (Figure 1A). When compared in terms of $k_{\mathrm{cat}} / K_{\mathrm{M}}$ or RSA $/ K_{\mathrm{M}}$ (where RSA is relative specific activity), GluRS and TyrRS (both class I) show the greatest selection against $\beta^{3}$ amino acid substrates (89- and $>900$-fold, respectively), with the effects on $k_{\text {cat }}$ or RSA (32and 46-fold, respectively) greater than the effects on $\mathrm{K}_{M}$ (2.9- and 21-fold, respectively) 
(Figure S4 and Table S2). In contrast, GlyRS and PheRS (class II) tolerate the expanded $\beta^{3}$ amino acid backbone, with both showing only an 8-fold selection $\left(k_{\mathrm{cat}} / K_{\mathrm{M}}\right)$ against $\beta^{3}$ amino acid substrates and roughly equivalent changes in $k_{\mathrm{cat}}$ and $K_{\mathrm{M}}$. The most tolerant enzyme evaluated was MetRS (class IA), which displays a modest (2-fold) preference for $a$ Met over $\beta^{3}$-Met during the adenylation phase and very similar values for both $k_{\mathrm{cat}}$ and $k_{\mathrm{m}}$.

Only slightly different conclusions about $\alpha$ - $/ \beta^{3}$-amino acid specificity are evident when the complete aminoacylation reaction is considered (Figure 1B). Indeed, when compared in terms of $k_{\mathrm{cat}} / K_{\mathrm{M}}$, GluRS and (especially) TyrRS still show the greatest selection against $\beta^{3}$ amino acid substrates (83- and 1500-fold, respectively). MetRS was slightly less tolerant, with a 19 -fold preference $\left(k_{\mathrm{cat}} / K_{\mathrm{M}}\right)$ for $a$-Met over $\beta^{3}$-Met. PheRS and GlyRS were again significantly more tolerant of the expanded $\beta^{3}$-amino acid backbone, with both showing only a 2-fold selection $\left(k_{\text {cat }} / K_{\mathrm{M}}\right)$ against $\beta^{3}$-amino acid substrates and roughly equivalent changes in $k_{\text {cat }}$ and $K_{\mathrm{M}}$ (Figure S5 and Table S3). The deacylation reaction was relatively insensitive to the amino acid backbone (Figure 1B, Figure S6 and Table S4). It remains to be established whether $\beta^{3}$-amino acid tolerance will be observed for other class II enzymes (such as SerRS and ThrRS (class IIA) or AspRS or LysRS (class IIB)). Nevertheless, the results raised the possibility that GlyRS and PheRS would catalyze the in vivo formation of tRNAs that are mis-acylated with $\beta^{3}$-Gly or $\beta^{3}$-Phe, respectively, or derivatives thereof.

To better understand the molecular basis for the observed differences in $\beta^{3}$-amino acid tolerance, we performed molecular dynamics (MD) simulations of TyrRS and PheRS, the aaRS enzymes representing the lowest and highest tolerance, respectively, for $\beta^{3}$-amino acid substrates. We began with crystal structures of E. coli TyrRS ${ }^{15}$ and PheRS ${ }^{16}$ and structures of $\beta^{3}$-Tyr and $\beta^{3}$-Phe modeled in Gaussian. MD simulations of TyrRS performed for $4 \mathrm{~ns}$ in the presence of $\mathrm{Mg}^{2+}$ and either $a$-Tyr or $\beta^{3}$-Tyr reveal significant differences in the position and dynamics of several TyrRS amino acids previously shown to promote adenylation (Figure S7). In particular, there were differences in the dynamics of K85, K89, K235, and K238, which include the essential KMSKS loop ${ }^{15}$ and their ability to support the hydrogenbond networks implicated in substrate binding and catalysis (Figure 2A). Perhaps most striking were differences in coordination of $\mathrm{Mg}^{2+}$ ions that stabilize the pyrophosphate leaving group. ${ }^{17}$ Two $\mathrm{Mg}^{2+}$ interact with the pyrophosphate when $a$-Tyr is present, while only one $\mathrm{Mg}^{2+}$ is found in the $\beta^{3}$-Tyr complex. Analogous MD simulations with PheRS revealed very few differences in the substrate-dependent dynamics of the MD trajectories orMg ${ }^{2+}$ coordination (Figures $2 \mathrm{~B}$ and $\mathrm{S} 7$ ). It has been hypothesized that class II aminoacyltRNA synthetases evolved to discriminate among amino acid substrates mainly by altering their amino acid binding pockets. ${ }^{18}$ Our results are consistent with this hypothesis, and further suggest that class II aaRS enzymes may represent better starting points for the development of orthogonal aaRS enzymes that selectively incorporate diverse $\beta^{3}$-amino acids.

Once aminoacylated, tRNAs are delivered to the ribosome by the translation factor EF-Tu in complex with GTP. In some cases, EF-Tu interacts principally with the tRNA body, while in others it interacts with the amino acid side chain; these interactions are balanced to ensure efficient delivery of all 20 natural $a$-amino acids. ${ }^{19}$ Poor EF-Tu binding and delivery of misaminoacyl-tRNAs is associated with inefficient incorporation of $N$-methyl amino acids, 
analogs with bulky side chains, and phosphorylated amino acids. ${ }^{7,20}$ In certain cases, EF-Tu re-engineering has been necessary to achieve high incorporation levels. ${ }^{21}$ To evaluate whether re-engineering would be necessary for tRNAs carrying $\beta^{3}$-amino acids, we made use of an RNase protection assay ${ }^{22}$ to determine how the equilibrium binding affinity for EF-Tu varies with $a$ - $/ \beta^{3}$-amino acid identity. For three of the five side chains evaluated (Gly, Glu, and Tyr), EF-Tu was relatively insensitive to the amino acid backbone, binding with roughly equal affinity to the acylated and mis-acylated cognate tRNA (Figure 3). In two cases (Met and Phe), EF-Tu showed a small preference (3-8-fold) for the $a$-amino acidcontaining tRNA but still bound the tRNA carrying the $\beta^{3}$-amino acid with a $K_{\mathrm{D}}$ in the nM range. As a difference of at least 10 -fold in $K_{\mathrm{D}}$ is required to impair EF-Tu binding and aminoacyl-tRNA delivery to the ribosome, ${ }^{7,23}$ we expected the small differences observed here to impact EF-Tu function minimally, allowing ribosome delivery of a diverse set of tRNAs mis-acylated with $\beta^{3}$-amino acids.

Building on the knowledge that E. coli PheRS effectively mis-aminoacylates tRNA ${ }^{\text {Phe }}$ with $\beta^{3}$-Phe (Figure 1) and that E. coli EF-Tu interacts efficiently with the $\beta^{3}$-Phe-tRNA ${ }^{\text {Phe }}$ complex (Figure 3), we asked whether E. coli expressing previously reported mutant ribosomes ${ }^{10,11}$ could support the incorporation of $\beta^{3}$-Phe analogs into DHFR in vivo. To begin, we chose the $\beta$-puromycin-sensitive ribosome that exhibited the highest suppression efficiency for translation in vitro with a tRNA chemically mis-acylated with $\beta$-Ar (Scheme S1A). This ribosome contains the mutant 23S sequence referred to as 040329 , with 13 base changes between residues 2057 and 2507. E. coli BL21(DE3) cells were transformed with a pLK35 plasmid encoding either wild type or $04032923 \mathrm{~S} \mathrm{rRNA}^{10}$ as well as one encoding DHFR with a single UUC codon at position 128 (Figure 4A). ${ }^{24}$ Cells were grown in the presence of 19/20 minimal media containing all $a$-amino acids except $a$-Phe and supplemented (or not) with $a$-Phe, $\beta^{3}$-Gly, $\beta^{3}$-Phe, or a brominated $\beta^{3}$-Phe derivative $\beta^{3}$ - $(p$ $\mathrm{Br}) \mathrm{Phe}$. Translated DHFR was isolated using a Ni(II)-nitrilotriacetic acid resin and analyzed by SDS-PAGE (Figure 4B) and mass spectrometry (Figure 4C).

As expected, BL21(DE3) cells expressing only wild type ribosomes generated only trace amounts of DHFR when grown in unsupplemented 19/20 minimal media or in media supplemented with $\beta^{3}$-( $p$-Br)Phe or $\beta^{3}$-Gly; higher levels of DHFR ( 8 -fold) were observed when $a$-Phe was added. Cells expressing 040329 ribosomes along with wild type ribosomes also generated trace amounts of DHFR when grown in unsupplemented 19/20media; however, in this case, significant levels of DHFR were observed when the media was supplemented with $\beta^{3}$ - $\left(p\right.$-Br)Phe or $\beta^{3}$-Gly as well as $a$-Phe. To confirm that $\beta^{3}$ - $(p-\mathrm{Br}) \mathrm{Phe}$ was incorporated at position 128 of the DHFR translated in these cells, the isolated full length $(19 \mathrm{kDa})$ DHFR was digested with trypsin and analyzed by LC-MS/MS (Figure 4C). Tryptic peptides comprising DHFR residues $127-149$ and containing either $a$-Phe or $\beta^{3}$ - $(p$ $\mathrm{Br}$ )Phe at position 128 were detected (Figure $4 \mathrm{C}$ ); no evidence for $\beta^{3}$-Gly incorporation was found. Spectral counting revealed a 30 -fold lower incorporation of $\beta^{3}-(p-\mathrm{Br}) \mathrm{Phe}$ relative to $a$-Phe (Table S6).

We hypothesized that ribosomes with improved efficiency and selectivity might be obtained by a more complete analysis of $23 \mathrm{~S}$ rRNA sequence space. Thus, we introduced additional diversity into the $04032923 \mathrm{~S}$ rRNA between positions 2496 and 2507, a region adjacent to 
the A-site, to generate $>8000$ unique clones (theoretical diversity $=8192$ ) and screened them to identify members that were both resistant to erythromycin $(6.8 \mu \mathrm{M})$ and sensitive to $\beta$ puromycin $(250 \mu \mathrm{M})$. Approximately 2000 clones were resistant to $6.8 \mu \mathrm{M}$ erythromycin, showing $<20 \%$ inhibition of growth relative to wild type (Figure S8A). The 2000 erythromycin-resistant clones were then screened for sensitivity to $250 \mu \mathrm{M} \beta$-puromycin (Figure S8B); in this case only $2 \%$ of the 2000 clones showed $>30 \%$ inhibition. Examination of the 44 sensitive clones revealed a preponderance of two 23S rRNA sequences: the previously reported 040329 mutant and a new mutant, P7A7, that differed from wild type at 12 positions within the $23 \mathrm{~S}$ rRNA, containing the sequence UGACUU at positions 25022507 (Figure S9).

Cells expressing P7A7 ribosomes along with wild type ribosomes also generated trace amounts of DHFR when grown in unsupplemented 19/20 minimal media, however in this case, higher levels of DHFR were observed when the media was supplemented with $a$-Phe or $\beta^{3}$ - $(p-\mathrm{Br}) \mathrm{Phe}$ (Figure 4B). To confirmthat $\beta^{3}$ - $(p$-Br)Phe was incorporated at position 128 of the translated DHFR in cells supplemented with this amino acid, the isolated full length DHFR was digested with trypsin and analyzed by LC-MS/MS as described above; tryptic peptides comprising DHFR residues 127-149 and containing either $a$-Phe or $\beta^{3}$ - $(p$-Br) $\mathrm{Phe}$ at position 128 were detected (Figure $4 C$ ). In this case, spectral counting revealed only a 10fold lower incorporation of $\beta^{3}$ - $(p$-Br)Phe relative to $a$-Phe (Table S6). Additional analysis revealed that the $\beta^{3}$ - $(p-\mathrm{Br}) \mathrm{Phe} / a$-Phe incorporation ratio was 3 -fold greater in cells expressing P7A7 ribosomes than in cells expressing 040329 ribosomes (Table S6). E. coli harboring P7A7 ribosomes grow with a doubling time only $14 \%$ longer than wild type (Figure S10).Although further work must define the changes within P7A7 ribosomes that lead to enhanced function, these data set the stage for the biosynthesis of $\beta^{3}$-amino acidcontaining proteins and peptides and suggest that the $E$. coli translation machinery could be engineered to incorporate many non-natural, non- $a$-amino acids into protein in vivo.

\section{Supplementary Material}

Refer to Web version on PubMed Central for supplementary material.

\section{ACKNOWLEDGMENTS}

We thank Tom Steitz, Virginia Cornish, Ruben Gonzalez, Shinsuke Sando, Albert Dahlberg, and Sid Hecht for plasmids or protocols and Pam S. P. Wang for preliminary experiments. W.E.R and AS.W. acknowledge the generous support of the NSF (DGE-1122492). D.S. was supported by NIGMS (GM22854).

\section{REFERENCES}

(1). O’Donoghue P; Ling J;Wang Y-S; Soll D Nat. Chem. Biol 2013, 9, 594. [PubMed: 24045798] Liu CC; Schultz PG. Annu. Rev. Biochem. 2010, 79, 413. [PubMed: 20307192] Chin JW Annu. Rev. Biochem. 2014, 83, 379. [PubMed: 24555827] Passioura T; Suga H Trends Biochem. Sci. 2014, 39, 400-408. [PubMed: 25129886]

(2). Noren CJ; Anthony-Cahill SJ; Griffith MC; Schultz PG Science 1989, 244, 182. [PubMed: 2649980] Bain JD; Diala ES; Glabe CG; Wacker DA; Lyttle MH; Dix TA; Chamberlin AR Biochemistry 1991, 30, 5411. [PubMed: 2036409] Ellman JA; Mendel D; Schultz PG Science 1992, 255, 197. [PubMed: 1553546] 
(3). Please see examples cited in ref 1 as well as: Lu T; Ting AY; Mainland J; Jan LY; Schultz PG; Yang J Nat. Neurosci 2001, 4, 239. [PubMed: 11224539] England PM; Zhang YN; Dougherty DA; Lester HA Cell 1999, 96, 89. [PubMed: 9989500] Ma H; Liu N; Shi S; Wang S; Chen Y RSC Adv 2015, 5, 39580.Gleitsman KR; Kedrowski SMA; Lester HA.; Dougherty DA. J. Biol. Chem. 2008, 283, 35638. [PubMed: 18952603] Gleitsman KR; Lester HA; Dougherty DA ChemBioChem 2009, 10, 1385. [PubMed: 19405066] Guo J; Wang J; Anderson JC; Schultz PG Angew. Chem., Int. Ed. 2008, 47, 722.

(4). See: Fujino T; Goto Y; Suga H; Murakami H J. Am. Chem. Soc. 2016, 138, 1962. [PubMed: 26807980] Sando S; Abe K; Sato N; Shibata T; Mizusawa K; Aoyama YJ Am. Chem. Soc. 2007, $129,6180-6186$ and references cited therein.

(5). Goto Y; Katoh T; Suga H Nat. Protoc. 2011, 6, 779. [PubMed: 21637198]

(6). Dedkova LM; Fahmi NE; Golovine SY; Hecht SMJ Am. Chem. Soc. 2003, 125, 6616.Englander MT; Avins JL; Fleisher RC; Liu B; Effraim PR; Wang J; Schulten K; Leyh TS; Gonzalez RL; Cornish VW. Proc. Natl. Acad. Sci. U. S.A. 2015, 112, 6038. [PubMed: 25918365] Subtelny AO; Hartman MCT; Szostak JW J. Am. Chem. Soc. 2008, 130, 6131. [PubMed: 18402453] Wang J; Kwiatkowski M; Forster AC ACS Chem. Biol. 2015, 10, 2187. [PubMed: 26191973]

(7). Ieong KW; Pavlov MY; Kwiatkowski M; Ehrenberg M; Forster AC RNA 2014, 20, 632. [PubMed: 24671767]

(8). Seebach D; Overhand M; Kuhnle FNM; Martinoni B; Oberer L; Hommel U; Widmer H Helv. Chim. Acta 1996, 79, 913.Geueke B; Heck T; Limbach M; Nesatyy V; Seebach D; Kohler HPE FEBS J. 2006, 273, 5261. [PubMed: 17064315] Heck T; Limbach M; Geueke B; Zacharias M; Gardiner J; Kohler HPE; Seebach D Chem. Biodiversity 2006, 3, 1325.Hook DF; Bindschadler P; Mahajan YR; Sebesta R; Kast P; Seebach D Chem. Biodiversity 2005, 2, 591.

(9). Guichard G; Zerbib A; Le Gal FA; Hoebeke J; Connan F; Choppin J; Briand JP; Guillet JGJ Med. Chem. 2000, 43, 3803.Reinelt S; Marti M; Dedier S; Reitinger T; Folkers G; de Castro JAL; Rognan DJ Biol.Chem. 2001, 276, 24525.Webb AI; Dunstone MA; Williamson NA; Price JD; de Kauwe A; Chen WS; Oakley A; Perlmutter P; McCluskey J;Aguilar MI; Rossjohn J; Purcell AW J. Immunol. 2005,175,3810. [PubMed: 16148127] Cheloha RW; Sullivan JA; Wang T; Sand JM; Sidney J; Sette A; Cook ME; Suresh M; Gellman SH ACS Chem. Biol. 2015, 10, 844. [PubMed: 25559929]

(10). Dedkova LM; Fahmi NE; Paul R; del Rosario M; Zhang L; Chen S; Feder G; Hecht SM Biochemistry 2012, 51, 401. [PubMed: 22145951]

(11). Maini R; Nguyen DT; Chen S; Dedkova LM; Chowdhury SR; Alcala-Torano R; Hecht SM Bioorg. Med. Chem. 2013, 21, 1088. [PubMed: 23375097] Maini R; Chowdhury SR; Dedkova LM; Roy B; Daskalova SM; Paul R; Chen S; Hecht SM Biochemistry 2015, 54, 3694. [PubMed: 25982410] Maini R; Dedkova LM; Paul R; Madathil MM; Chowdhury SR; Chen S; Hecht SM J. Am. Chem. Soc. 2015, 137, 11206. [PubMed: 26301427]

(12). Hartman MCT; Josephson K; Szostak JW Proc. Natl. Acad. Sci. U. S.A. 2006, 103, 4356. [PubMed: 16537388] Hartman MCT; Josephson K; Lin CW; Szostak JW PLoS One 2007, 2, e972.Ko J.-h; Wang Y-S; Nakamura A.; Guo L-T; Söll D.; Umehara T. FEBS Lett. 2013, 587, 3243. [PubMed: 23994531]

(13). Beebe K; Waas W; Druzina Z; Guo M; Schimmel P Anal. Biochem. 2007, 368, 111. [PubMed: 17603003] Bruzzese FJ; Tsu CA; Ma J; Loke HK; Wu D; Li Z; Tayber O; Dick LR Anal. Biochem. 2009, 394, 24. [PubMed: 19602421]

(14). Ledoux S; Uhlenbeck OC Methods 2008, 44, 74. [PubMed: 18241789]

(15). Kobayashi T; Takimura T; Sekine R; Vincent K; Kamata K; Sakamoto K; Nishimura S; Yokoyama SJ Mol. Biol. 2005, 346, 105.

(16). Mermershtain I; Finarov I; Klipcan L; Kessler N; Rozenberg H; Safro MG Protein Sci. 2011, 20, 160. [PubMed: 21082706]

(17). Leatherbarrow RJ; Fersht AR; Winter G Proc. Natl. Acad. Sci. U.S.A. 1985, 82,7840. [PubMed: 3865201]

(18). Kavran JM; Gundllapalli S; O’Donoghue P; Englert M; Soll D; Steitz TA Proc. Natl Acad. Sci. U. S. A. 2007, 104, 11268. [PubMed: 17592110]

(19). LaRiviere FJ; Wolfson AD; Uhlenbeck OC Science 2001, 294, 165. [PubMed: 11588263] 
(20). Ieong KW; Pavlov MY; Kwiatkowski M; Forster AC; Ehrenberg MJ Am. Chem. Soc 2012, 134, 17955.Miller C; Brocker MJ; Prat L; Ip K; Chirathivat N; Feiock A;Veszpremi M; Soll D FEBS Lett. 2015, 589, 2194. [PubMed: 26160755]

(21). Ohtsuki T; Yamamoto H; Doi Y; Sisido MJ Biochem. 2010, 148, 239.Park HS; Hohn MJ; Umehara T; Guo LT; Osborne EM; Benner J; Noren CJ; Rinehart J; Soll D Science 2011, 333, 1151. [PubMed: 21868676]

(22). Pleiss JA; Uhlenbeck OC J. Mol. Biol. 2001, 308, 895. [PubMed: 11352580]

(23). Mittelstaet J; Konevega AL; Rodnina MV J. Am. Chem. Soc. 2013, 135, 17031. [PubMed: 24079513]

(24). Kanatani K; Sando S; Aoyama Y Nucleic Acids Symp. Ser. 2005, 49, 265. 


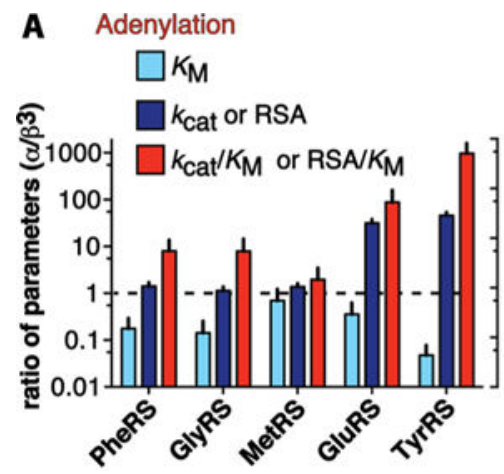

B Aminoacylation

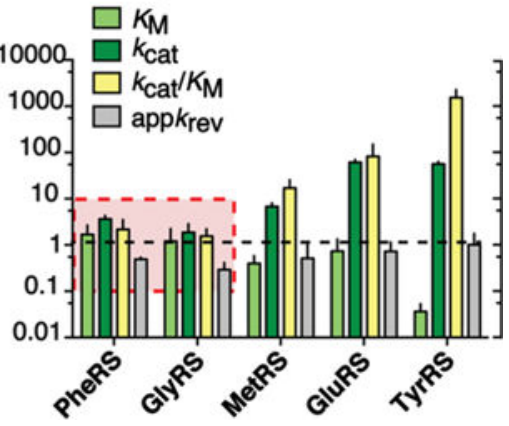

Figure 1.

Kinetic parameters associated with $a$ - and $\beta^{3}$-amino acid (A) adenylation, (B) aminoacylation, and deacylation. The $y$-axis of each plot shows the ratio $\left(a / \beta^{3}\right)$ of the measured kinetic parameters. 

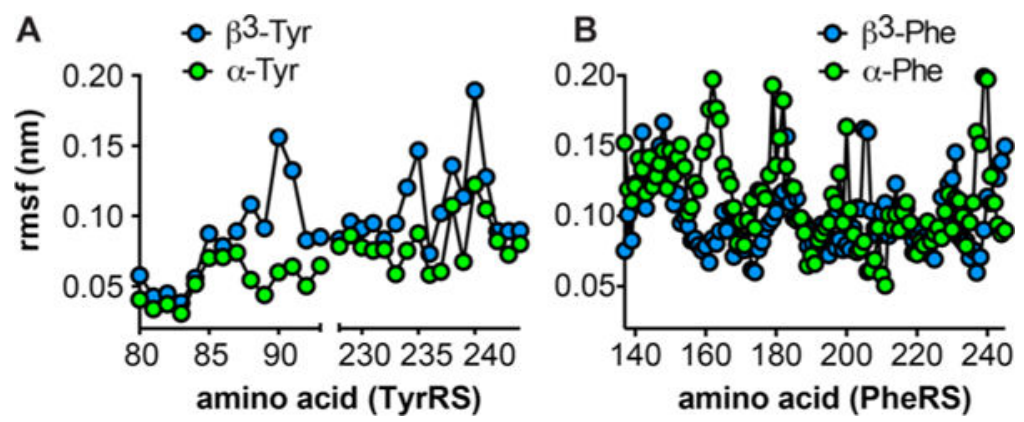

Figure 2.

MD simulations detect differences in structure and dynamics of (A) TyrRS but not (B) PheRS when bound to $a$ - and $\beta^{3}$-amino acids. Plots show atom-averaged root-mean-square fluctuations (rmsf) of the indicated amino acids by residue number. 


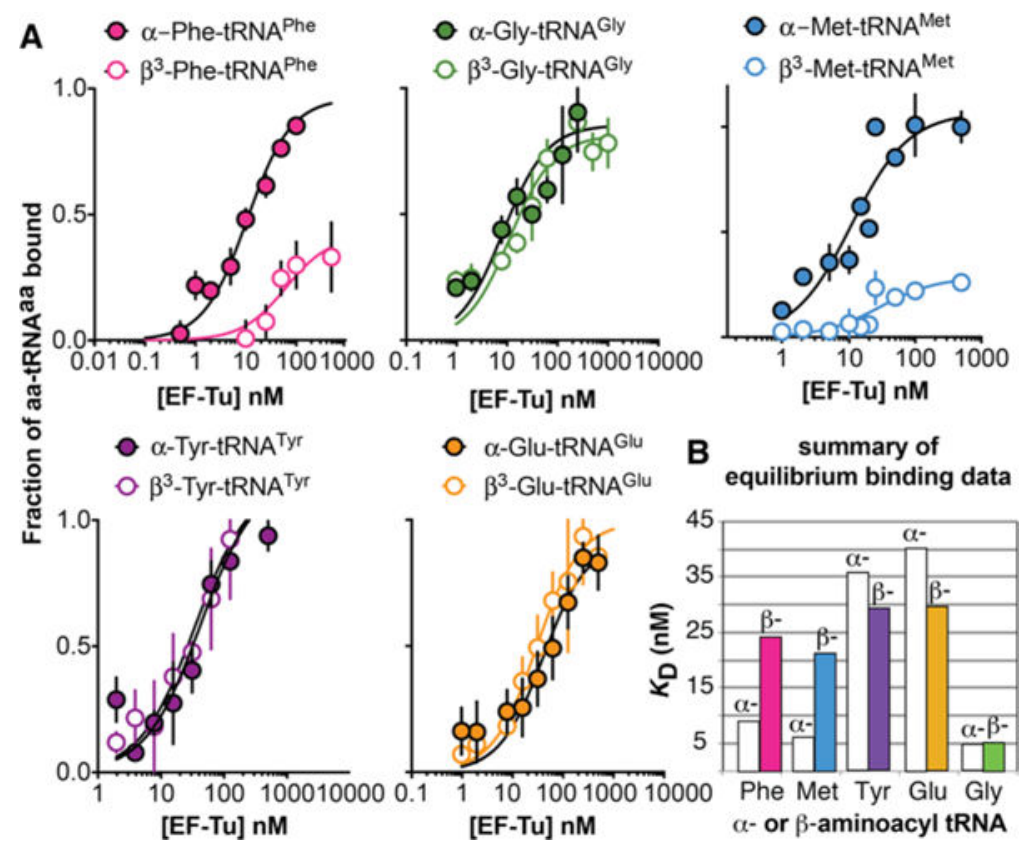

Figure 3.

EF-Tu specificity. (A) Plots showing the fraction of [ $\left.{ }^{32}-\mathrm{P}\right]$-aminoacyl-tRNA bound as a function of [EF-Tu]. Fits show binding isotherms for a tight-binding ligand exhibiting no cooperativity. (B) Plot showing how $K_{\mathrm{D}}$ varies with amino acid backbone. 
A
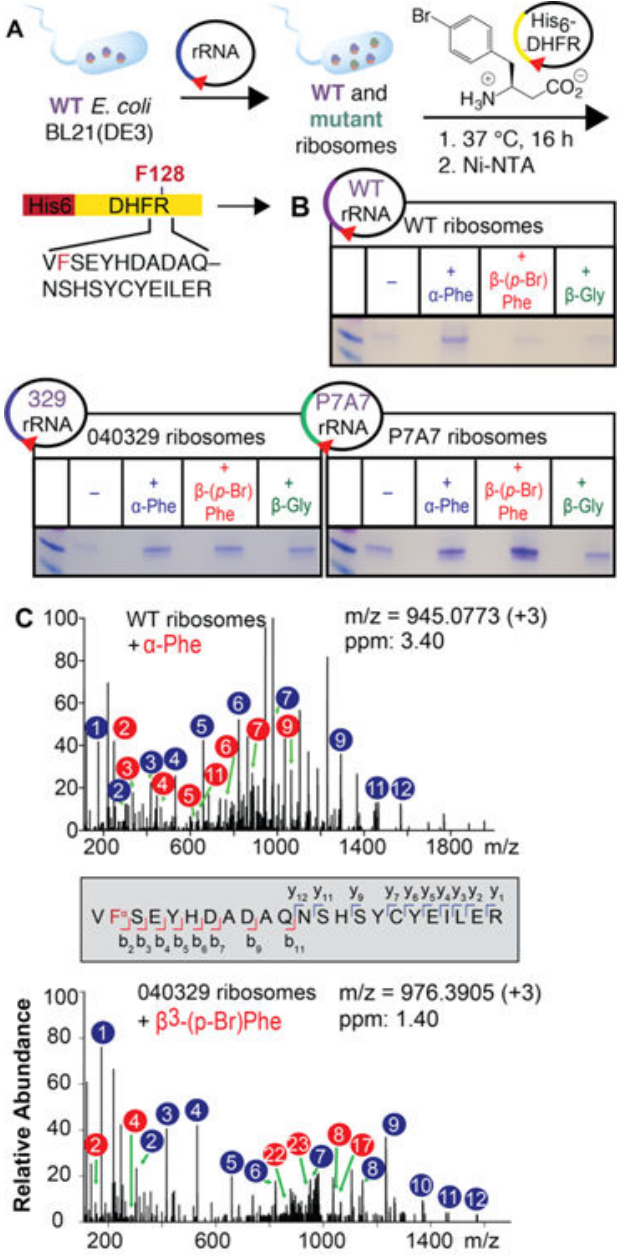

VFISEYHDADAQNSTHSYCYEILER
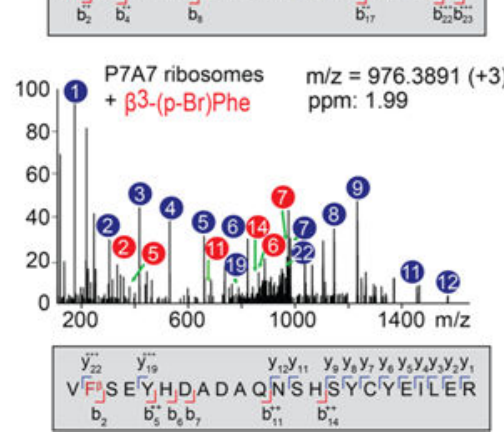

Figure 4.

In vivo incorporation of $\beta^{3}$-Phe analogs by $E$. coli harboring mutant ribosomes. (A) Experimental strategy. (B) SDS-PAGE analysis of $\mathrm{His}_{6}$-DHFR products after enrichment with Ni-NTA. (C) LC-MS/MS data. DHFR expression yields were consistently 17-28 mg/L. 